This item was submitted to Loughborough's Research Repository by the author.

Items in Figshare are protected by copyright, with all rights reserved, unless otherwise indicated.

\title{
Young students learning formal algebraic notation and solving linear equations: are commonly experienced difficulties avoidable?
}

PLEASE CITE THE PUBLISHED VERSION

http://dx.doi.org/10.1007/s10649-012-9394-x

\section{PUBLISHER}

(C) Springer Science+Business Media B.V.

\section{VERSION}

AM (Accepted Manuscript)

\section{PUBLISHER STATEMENT}

This work is made available according to the conditions of the Creative Commons Attribution-NonCommercialNoDerivatives 4.0 International (CC BY-NC-ND 4.0) licence. Full details of this licence are available at: https://creativecommons.org/licenses/by-nc-nd/4.0/

\section{LICENCE}

CC BY-NC-ND 4.0

\section{REPOSITORY RECORD}

Hewitt, David P.L.. 2019. "Young Students Learning Formal Algebraic Notation and Solving Linear Equations: Are Commonly Experienced Difficulties Avoidable?". figshare. https://hdl.handle.net/2134/18177. 


\title{
Young students learning formal algebraic notation and solving linear equations: are commonly experienced difficulties avoidable?
}

Dave Hewitt

School of Education, University of Birmingham, UK

\begin{abstract}
This study looks at a mixed ability group of 21 Year 5 primary students (aged 9-10 years old) who had previously never had formal instruction using letters to stand for unknowns or variables in a mathematics context; nor had they been introduced to formal algebraic notation. Three lessons were taught using the computer software Grid Algebra where they began working with formal notation and were solving linear equations with some degree of success by the end of the lessons. The teaching was such that nothing was explained or justified by the teacher explicitly. The students appeared either not to meet, or to overcome quickly, some of the difficulties identified within previous research studies. They demonstrated remarkable confidence working with complicated linear algebraic expressions written in formal notation. A key feature of the software activities was that formal notation continually needed to be used and interpreted, and the software provided neutral feedback which enabled the students to educate their interpretation of the notation.
\end{abstract}

Keywords algebra computers misconceptions technology

\section{Introduction}

There have been many studies identifying difficulties students experience with algebra and this paper seeks to show that these difficulties are not an inevitable consequence of working on algebra. Furthermore, students as young as 910 years old are able to engage with relatively complex formal algebraic notation in a meaningful way whilst completing substitution tasks and solving linear equations. The design of the computer software Grid Algebra ${ }^{l}$ provides features which are significant in helping students learn the order within algebraic notation without the need for mnemonics such as BIDMAS or PEMDAS (used in the UK and US respectively, see below). They can be confident with formal notation which has been found to be difficult for older students and which is far more complex than that involved in other studies of young students working meaningfully with letters (for example, Carraher et al., 2001; Dougherty and Zilliox, 2003; Schliemann et al., 2003). The software environment also allows students to treat expressions both as objects in their own right as well as a process to be carried out, thus avoiding one of the common difficulties identified within the literature. I begin the paper with a discussion of some of these difficulties and go on to discuss a project involving the use of the software Grid Algebra with a mixed ability Year 5 group of students (9-10 year olds). These students had previously never met letters as notating variables in a mathematical context nor any formal algebraic notation. Studies cited above have shown that students of this age are capable of working algebraically with letters but in this study I will show that they can work confidently with far more complex formal algebraic notation than previously considered. Indeed they were solving relatively complex linear equations, albeit with some students using the visual support offered by the software. Also, some commonly observed difficulties, such as learning order of operations and seeing expressions as objects as well as processes, were either not present or were overcome quickly. I will argue that a key factor in this is the role the software played in the students' learning. The software created formal expressions through movements in a grid and these expressions were viewed as historical artefacts of the journeys made. The stress was placed on the journey rather than the numerical result of that journey and as such expressions were treated as objects before they were later viewed as processes. This reverses the usual development described by APOS theory (Cottrill et al., 1996; Dubinsky, 1991) where actions are developed into processes which might later turn into objects. I will argue that another significant feature of the software was the neutral feedback it offered. This enabled students to learn the order of operations without explicit instruction or use of mnemonics.

\footnotetext{
${ }^{1}$ Grid Algebra is available from the Association of Teachers of Mathematics (http://www.atm.org.uk/shop/products/sof071.html)
} 


\section{Difficulties students experience}

There has been a substantial literature on the difficulties that many students experience when learning algebra. This includes difficulties with the equals sign, wanting to collapse expressions to a single 'answer' and a variety of meanings given to letters which are not commensurate with their standard usage in algebra (Collis, 1974; 1975; Küchemann, 1981; Kieran, 1981; Herscovics, 1989; Cooper et al., 1997; Knuth et al., 2005; Linsell and Allan, 2010). Dubinsky (1991) built on Piaget's work on reflective abstraction to consider the development of schemas through stages involving carrying out processes and the creation of objects. This was later coined APOS theory (Cottrill et al., 1996) where there is an order of Action, Process, Object and Schema which occurs frequently in the learning of mathematics. Sfard (1991) pointed out that work within algebra requires an expression such as $3(x+2)-1$ to be viewed both as a process and as an object. Students often have difficulty treating expressions as an object since their common experience before the introduction of algebra has been to carry out any operations which appear in an expression. So when they meet an expression such as $5+n$, they attempt to squash it down to a single entity with no operation showing, such as $5 n$ (MacGregor and Stacey, 1997). This form of conjoining is indicative of an inability to treat expressions as objects. Gray and Tall (1994) labelled as "proceptual" thinking the ability to be flexible in the way an expression is treated: as a process and as a conceptual object.

Van Amerom (2003) found that students in grades 6 and 7 were able to solve equations but formal symbolising was a major obstacle. The act of inventing symbolism is not so much the issue. Hughes (1990) found that three to five year olds can invent symbols to represent quantities. Steffe and Olive (1996) also noticed that young children can invent notations for arithmetic operations. Giving a label for something is a natural activity which all children engage upon from an early age. However, it is a difficult task to interpret someone else's notation (Sáenz-Ludlow and Walgamuth, 1998). As Sfard and Linchevski (1994) point out - both historically and with learning - algebraic thinking appears before notation. For the creators of notation, they already have an algebraic awareness which they are choosing to notate. Which notation they choose is a matter of preference not a matter of right or wrong. However, for students learning formal notation, all they are given is a collection of someone else's symbols and for them it is not a matter of preference but a matter of getting it right or wrong.

Learning any form of language is not as easy as a one-to-one correspondence between signifier and signified (Deacon, 1997). There are elements of a metaphorical relationship between symbols and objects/ideas but there is also a metonymic relationship between symbols themselves. This is so with mathematical notation where the meaning for the symbol ' 2 ' will change according to the symbols around it. For example 24, 42, 4 ' and $\frac{4}{2}$ all result in different meanings for the symbol '2'. As Mercer (2000, p. 67) said "words gather meanings from 'the company they keep'."

The order of operations within an expression also causes difficulty. Unlike written language, mathematical notation does not have a strict left-to-right order and the reading of formal notation requires students to know several conventions. These can be context dependant with, for example, concatenation (the placing of one symbol next to

another) sometimes meaning addition (as with $5 \frac{3}{4}$ where this means $5+\frac{3}{4}$ ), and sometimes meaning multiplication (as with $5 x$ where this means 5 multiplied by $x$ ). Some mnemonics are created such as BIDMAS in the UK (Brackets, Indices, Division, Multiplication, Addition and Subtraction) to try to help students learn the conventions of ordering, so that $5+3 \times 2$ is accepted in the mathematics community to equal 11 and not 16 . However, even these mnemonics can create difficulties as there is also the convention that addition and subtraction are considered to be equal even though addition appears before subtraction in the mnemonic. The convention is then that the order is read left-to-right. Thus $7-3+2$ is considered to be 6 whereas someone who considers that addition must happen before subtraction might read this as $7-(3+2)$ and get 2 . The same is true of multiplication and division. Glidden (2008) carried out a study about order of operations with 381 prospective teachers in the USA, who reported feeling 
confident in their own mathematics. $30.9 \%$ incorrectly carried out addition before subtraction and $38 \%$ incorrectly carried out multiplication before division in expressions which should have been read left-to-right. This is likely to be due to the order in which these operations are expressed in the American mnemonic PEMDAS (Please Excuse My Dear Aunt Sally). The letters stand for Parentheses, Exponents, Multiplication, Division, Addition and Subtraction. A problem with such mnemonics is that the conventional equal status given to multiplication and division, and addition and subtraction, is not made clear with one operation necessarily coming ahead of another in the mnemonic. The conflict between the left-right ordering of symbols in natural language and the not so straight forward ordering within some algebraic expressions is what Tall and Thomas (1991) describe as the parsing obstacle. They give the example of $2+3 x$ where it is read left-to-right whilst being calculated right-to-left.

\section{What students can do}

Research in the 1980s and 1990s, some of which is cited above, tended to focus on difficulties students experienced with algebra. Since then there have been several studies that have identified what students are able to do. Eight year old students can express algebraic relationships (Radford, 2010) and represent unknown values with letters and make mathematical statements with them (Carraher et al., 2001). Dougherty and Zilliox (2003) worked with children as young as six with ideas based upon the work of Davydov (1975) and found that those children could work with writing expressions with letters which represent relationships between attributes. So there is a contrast between research showing that many students experience difficulties with algebra with the increasing evidence that students are able to work with algebraic notions from a relatively young age.

\section{Theoretical framework}

Formal algebraic notation is an example of a social convention. We write $4 \times a$ as $4 a$ not because we have to but because someone began doing so and this usage has become accepted within the mathematics community. The way multiplication is written is an example of those things I call arbitrary - names and conventions. These are the result of social conventions. Different decisions could have been made and the same mathematics would be true except it would be expressed and named in different ways. A square is called a square in the English-speaking world but is carré in French, cuadro in Spanish and quadrat in German. There are many ways in which a square can be named as it is a matter of choice. The co-ordinate $(2,3)$ with reference to conventional $x$ and $y$ axes means two to the right horizontally and three up vertically. However, we could have decided that it meant two up and three to the right. Consistency and the ability to communicate is what is important rather than necessity. The number of degrees in a whole turn is 360 not because it has to be but because of a historical reason concerned with the Babylonians working with base 60. I call names and conventions arbitrary because for a learner they can feel arbitrary since there is no reason why they must be how they are. I have argued (Hewitt, 1999) that learning the arbitrary concerns acceptance and adoption rather than trying to understand why something is how it is, since it could always have been something different. The introduction of the notation of juxtaposition for multiplication in classrooms can lead to confusion for students as they cannot see why we need to write $4 a$ when they have spent most of their life writing " $x$ " for multiplication and seeing their teachers and text books writing it that way. As Lee and Messner (2000, p. 178) commented "The conventions of ordering in concatenations and in multiple operation situations need to be taught and reinforced, not "discovered"." There is nothing to "discover" since it does not have to be that way and so there is no logical or deductive thinking that would lead to knowing that this is how things are written in algebraic notation.

Mathematics lies within properties and relationships where something is correct not merely because it conforms to a social convention but because it can be justified as having to be how it is. The world of properties and relationships I call the necessary (Hewitt, ibid). These are things that have to be so (given certain assumptions), a world of justification rather than choice. For example, it is necessary that $3(x+4)$ gives the same numerical result as $3 x+12$ no matter what value $x$ takes; it is necessary that if $\frac{4(k+1)}{2}-6=34$ and $k$ is a real number then $k$ must equal 19 . 
This is the case no matter if I choose to write this in words, formal notation, or some other way. Thus I differentiate between the arbitrary, which is the choice of notation, and the necessary, which is the fact that $k$ must equal 19 irrespective of the notation used to express the equation.

The pedagogic implications of the arbitrary and necessary divide is that there are distinctly different challenges for both teacher and student for each of these. For the arbitrary, since it is about choice, a student cannot be expected to know what has been chosen. How would a student know that a circle is divided up into 360 units without being told in one way or another? How would a student know that a number that divides into 82 is called a factor of 82 without being told? A student needs to be informed of the arbitrary. Consequently, a teacher's role is to inform students and to help them memorise: assisting memory.

It is quite different for what is necessary, since this is something which must be the case and cannot be anything different. Therefore it is not something students need to be informed about. As long as the property or relationship is carefully chosen, students can use their existing awareness to become aware of something new. In this way they come to know something to be true because of mathematical reasons and not through memorisation of an arbitrary fact. As such a teacher's role is to provide suitable activities and make use of questioning to educate a student's awareness: educating awareness.

\section{The study}

The general aims of the study included finding whether a mixed ability group of 21 Year 5 students (9-10 year olds) from an inner city primary school in the West Midlands, UK, were able to engage with complex formal algebraic notation. In addition, I wanted to see how the visual and dynamic nature of the software assisted with, or created difficulties for, their learning of the algebraic topics of order of operations, substitution and solving linear equations. The students were taught a total of just three lessons lasting one hour for the first lesson and one and a half hours each for the other two lessons. The reason for the limited number of lessons was based upon two factors; firstly I was interested to find out how much the students might be able to learn within a relatively small amount of time, and secondly there was pressure for the students not to be away from their normal curriculum for too long. The students' mathematics attainment was described by their teachers in terms of the UK National Curriculum levels. These are designed to give a sense of student development across their time in school from primary through to secondary school up to the age of 16 . The levels are from one to eight with further achievement being judged as 'exceptional performance'. At the end of primary school the government's expected level is for students to achieve a level four. The students in this study were judged by their teachers to be from National Curriculum (NC) level two to level five. Three students were judged to be level 5, another three at level 4, 13 students at level 3 and two students at level 2 . The students in the school generally performed below the national average in the national tests taken in Year 6 at the end of primary school, and the proportion of students who received free school dinners was above the national average.

Before these three lessons began, none of the students had been taught formal algebraic notation and letters had not been introduced as standing for unknowns or variables. The lessons were taught by myself, mainly using the software Grid Algebra on an Interactive Whiteboard with a whole class focus. Occasionally students worked on paper exercises based upon the software and there were two half hour sessions in a computer room where students worked on computer-generated tasks provided within the software package. A significant aspect of the style of teaching was that nothing was ever explained to the students, including the particular appearance of formal notation. Instead there was extensive use of questioning and carefully chosen tasks. Many of these tasks involved students coming up to the board and using the interactive nature of the board to move expressions around the grid within the software.

All three lessons were video recorded with a camera focusing on the Interactive Whiteboard. A second camera was used in the first two lessons which faced the students in order to capture their expressions and gestures, and also to 
help identify which student was speaking. This second camera was not available in the third lesson. When students were working on pencil and paper tasks or working on computers in the computer room, a roaming camera was used. In addition, two pairs of students' computer work were recorded using Camtasia software which captured internally on the computer what happened on the screen. Worksheets were also collected in along with notebooks used by students during the whole class sessions.

The notion of arbitrary and necessary was the main lens through which the students' learning in this study was analysed. The videos were coded based upon existing sensitivities, such as arbitrary and necessary. Particular attention was paid to when notation was introduced and how students appeared to interpret that notation within the mathematical tasks carried out. There was also an element of grounded theory used (Strauss and Corbin, 1990) wherein patterns in student work were linked to other known research such as on the divide between arithmetic and algebra (Filloy and Rojano, 1989; Herscovics and Linchevski, 1994). These sensitivities increased the likelihood of future noticing of related events during the analysis process (Mason, 2002).

It is important for the reader to be aware that I wore three hats during this study; researcher, teacher and also the person who had developed the software. As such my comments and analysis have to be read with this in mind.

\section{Grid Algebra}

The notion of arbitrary and necessary is built into the design of Grid Algebra in that the notation, being arbitrary, is provided by the software. In contrast, no instruction is provided for the necessary. The noticing of algebraic aspects, such as how to multiply out brackets or solve equations, requires students to engage in activities and educate their own awareness of such matters. Support for that learning is provided by the software, but that support is neutral, non-judgmental and non-explanatory. Examples of the role the software plays in developing both the arbitrary and necessary are given later in analysis of excerpts from the lessons.

\begin{tabular}{|c|c|c|c|c|c|c|}
\hline \multicolumn{7}{|c|}{ 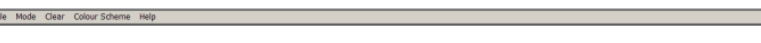 } \\
\hline \multirow{6}{*}{ 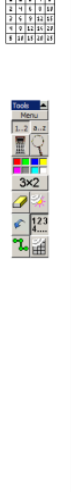 } & 1 & 1 & 2 & 3 & 4 & 5 \\
\hline & 2 & 2 & 4 & 6 & 8 & 10 \\
\hline & 3 & 3 & 6 & 9 & 12 & 15 \\
\hline & 4 & 4 & 8 & 12 & 16 & 20 \\
\hline & 5 & 5 & 10 & 15 & 20 & 25 \\
\hline & 6 & 6 & 12 & 18 & 24 & 30 \\
\hline & & & & & & \\
\hline
\end{tabular}

Fig 1 the multiplication grid structure behind Grid Algebra

Grid Algebra is based on a grid of multiplication tables (see Fig 1). Row one has the one times table, row three has the three times table, etc. Scroll bars exist so that it is possible to scroll further along these times tables, or scroll down to reveal other times tables. The number of rows can be changed and for most of the time in this study only two rows were visible, the one and two times tables.

Through the use of tools, individual numbers can be rubbed out to leave certain cells blank or all cells can be cleared leaving only the labels for the rows which appear on the left hand side of the grid. When the grid is blank a number can be dragged into a cell from a 'number box' which can be seen at the bottom of the screen in Fig 1. The number 
would then determine the rest of the grid. For example, in Fig 2 the presence of number 21 means that the shaded cells must now be 19 (subtracting 2 from 21 in row 1) and 42 (in row 2, doubling the 21).

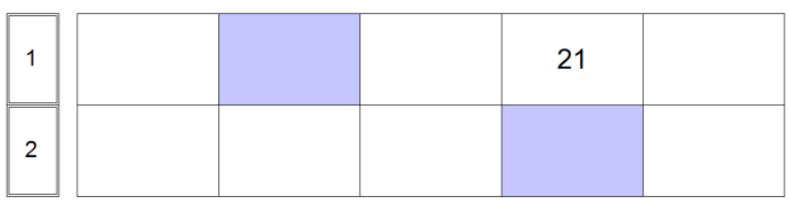

Fig 2 a number placed in an otherwise empty grid determines the values of all the other cells

A key aspect of Grid Algebra is that it can express the operations carried out when moving from one cell to another. For example, moving from the number 2 to the number 3 in row one involves adding one and with the software the number 2 can be picked up and dragged one cell to the right so that it will show $2+1$ in the cell which previously had 3 in it (see Fig 3).

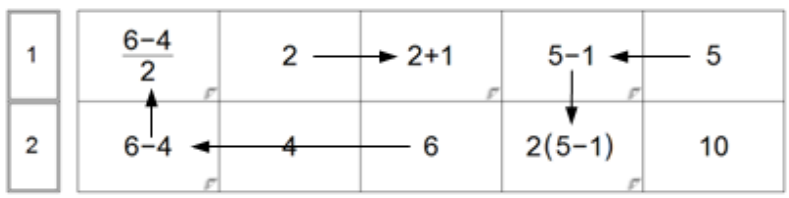

Fig 3 some possible movements from one cell to another

A peeled-back corner appears in the bottom right corner of this cell which indicates that there is also something else in that cell, in this case it is the original number 3. Likewise, if the number 5 in row one is dragged one cell to the left, then it will show 5-1. This can be viewed as a process to be carried out to produce the number 4 which is also in the same cell. Indeed a magnifier can be placed into this cell to produce a new window showing everything in that cell, connected by the "=" sign (Fig 4).

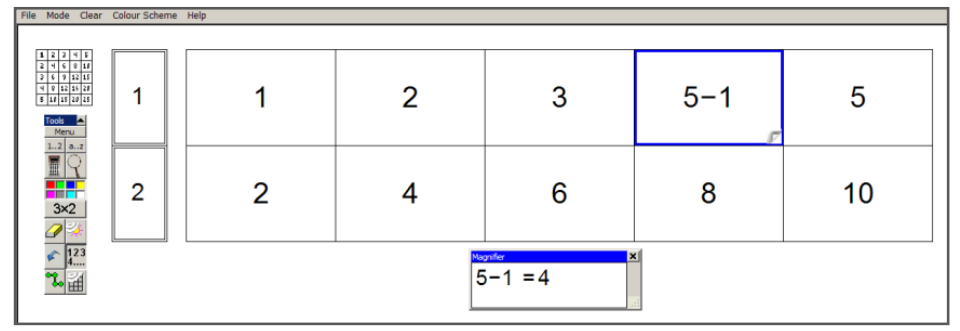

Fig 4 a magnifier can be dropped into a cell to reveal everything within that cell

The expression 5-1 can be dragged down from the one times table to the two times table and this would result in multiplying it by two and produce the expression 2(5-1), as in Fig 3. So the expression has been made from two movements, starting at 5 in row 1, moving one to the left and then moving down. In a similar way, the expression $\frac{6-4}{2}$ has been obtained from dragging 6 two cells to the left (this resulting in subtracting four due to it being in row two) and then up. There is a deliberate association between physical movements and abstract mathematical operations, with right-left being addition-subtraction and down-up being multiplication-division. This association allows students to bring their already known world of movement to the new and more abstract world of formal notation. Tall (2004) describes old experiences as 'met-befores' and has highlighted how some met-befores can cause confusion when students are introduced to new topics. He offers the example of whole numbers where 
students learn that there is always a 'next' number with no others in between and how this can cause difficulties when they come to learn about fractions. A fraction does not have a 'next' fraction and any two fractions have an infinite number of fractions between them. Not all met-befores occur within the mathematical world and there are many other experiences that can be accessed in a way where they become relevant to mathematics learning. Grid Algebra makes use of the met-befores of movement, such as implicitly knowing that if you move your hand a certain distance in one direction, then to return to the original position you need to move your hand the same distance in the opposite direction. Through linking movement with mathematical operations, this implicit knowledge supports the mathematical learning of inverse operations, where the inverse of adding six is subtracting six. Likewise reversing a series of movements means that the last movement is undone first and that relates to inversing a series of mathematical operations which appear in an expression.

The software has many other features but only those relevant to this paper will be mentioned as I discuss some parts of the lessons below.

The three lessons were structured to address certain key developments (timings given below are those for whole class activities unless stated otherwise):

- Number activities (getting to know the structure of the grid) - approx 20 minutes +5 minutes paper activity (lesson 1)

- Movements within the grid (meeting notation) - approx 17 minutes (lesson 1)

- Using notation to re-create journeys (learning order of operations) - approx 20 minutes +15 minutes on computer-generated activity (lessons $1 \& 2$ )

- Repeating activity of re-creating journeys whilst letters were introduced and work on writing as well as reading expressions (accepting formal notation with letters, letters as variables) - approx 13 minutes (lesson 2)

- Substitution (seeing letters as particular numbers) - approx 10 minutes +20 minutes on optional computergenerated tasks* (lesson 2)

- Different routes from the same start cell to the same end cell (multiplying out brackets) - approx 10 minutes +20 minutes on optional computer-generated tasks* (lesson 2)

- $\quad$ Finding the letter, given an expression involving that letter (inverse operations) - approx 36 minutes +15 minutes paper activity (lesson 3 )

- Placing a number in the same cell as the final expression and taking the number on the inverse journey to find the value of the letter (solving equations) - approx 17 minutes +12 minutes paper activity (lesson 3 )

(*Note: the students had 20 minutes where they could choose which computer-generated task they did; substitution or multiplying out brackets)

This paper will focus on only certain aspects which give a sense of the development of students' confidence with formal notation and their understanding leading up to solving equations. I will look at three particular steps on that journey: meeting notation; a 're-creating journeys' activity where notation is used as a tool rather than seen as an end product; and the shift to justification when working on inverse and solving equations. The reason for these choices is to: (a) give a flavour of the development of activity over time throughout the three lessons; (b) bring out key aspects of how students met notation, began to interpret that notation, and used the notation with confidence; and (c) examine the interplay between the arbitrary notation and the necessary mathematics.

Following this analysis, I will return to some of the issues raised in the literature above and consider the role played by the software. 


\section{Meeting notation}

The first movement on the grid that was made involved dragging the number 2 (in row 1) one cell to the right to produce $2+1$ (see Fig 1). When the students were asked "what is this?" $(2+1)$ they replied "three". This fitted in with seeing $2+1$ as a process to be carried out. A second movement was made taking the number 1 and moving it to the right to the cell with 4 in it. This produced $1+3$. When asked what number was underneath $1+3$ they said "four". This continued to stress the process of carrying out operations. However, they were next asked to write down on paper what it would say when 5 was moved to the cell with 3 in. This meant they were asked to write down the process, rather than carry out the process. Although they were all successful at correctly writing this down, and other movements I made along row 1, several were still thinking in terms of single numbers. For example, when I had made two movements to create $2+1+2$, some students were heard saying "that's five", "that's five, yes". As I carried on asking them to write down what certain movements would end up saying, seven of the 21 notebooks collected at the end of the teaching sessions showed use of an equals sign (see Fig 5) despite only being asked to write down what they would see after the movements were carried out.

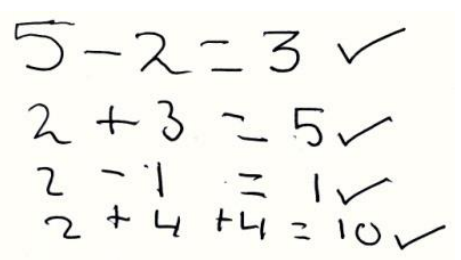

Fig 5 carrying out a calculation despite not being asked to do so

Interestingly two of those seven students stopped writing the equals sign after the first three such questions. They may have realised that attention was not being placed on calculating any of these (see Fig 6). In fact the software encourages seeing the equals sign as connecting equivalent expressions within a cell rather than the act of calculating. This is crucial to helping students see an expression as an object as well as a process which Sfard (1991) highlighted as being important for work in algebra.

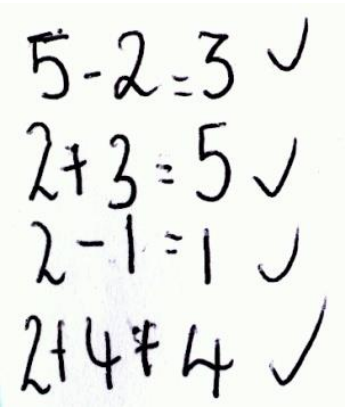

Fig 6 the last expression was left alone

As further movements were made involving a combination of multiplication, division, adding and subtracting the writing of an equals sign stopped being present on all but two of the students' books. The fact that an action (movement on the grid) created an object (notational expression), indicated a shift from the usual APOS (Dubinsky, 1991; Cottrill et al., 1996) order of events: Action, Process and then Object. Here an action created an object with attention taken away from a process.

Generally, students were asked to articulate what any movement meant in terms of operations before the movements were made. This meant, for example, that when the expression $2+1$ was about to be moved down from row 1 to row 2 , the students said that it would be multiplying by two. Thus, when the notation $2(2+1)$ appeared they already had a 
meaning they could place into the notation, rather than meeting the notation first and then trying to work out a meaning. There was no noticeable reaction to the appearance of brackets nor to the non-appearance of the multiplication sign. However, students did react when a division appeared as $\frac{8}{2}$. There were some comments such as "oh", "fraction", "it's a fraction but it stands for divide". This reaction was not surprising given that in their schooling so far this form of notation was exclusively used for expressing fractions, with division being written as $8 \div 2$. This reaction only occurred on this first appearance of the division line. There were no noticeable reactions at any subsequent time when division was carried out. The second occasion which created a reaction from students was when the expression $\frac{8-4+6}{2}$ in row one was moved to the left to create $\frac{8-4+6}{2}-1$. Before making this movement they had been invited to consider what it would look like and when the movement was made there was an immediate reaction of "yes!" from some students closely followed by "uh?" One student said "why'd the one have to go there?" Of course, it did not have to go there since notation is arbitrary and I deliberately made a decision not to engage with that question. In fact I felt the question was not addressed to me but was just an expression of what that student was thinking about. He did not appear to seek an answer from me. So even though there was a sense of surprise and even initial confusion, no-one actually asked me to explain the notation. I also made a point of moving on to other movements where the notation would be seen again, rather than dwelling on the first occurrence of the notation. Retrospectively I feel my invitation for them to consider how the subtraction might be written without first allowing them to see an example was ill judged. Notation is arbitrary and as such there is nothing for them to work out or 'discover'. Anything they write would only be an idea, a suggestion. They would only know they were right when they saw how the software did write it. Except for these short initial reactions, students never again questioned nor had any noticeable reaction to the formal notation as it appeared, even when we began getting quite complex expressions.

The learning of someone else's notation seemed to be accepted and not questioned. Rather than trying to persuade a student to write using a particular notation, it was accepted as the way in which the computer wrote things. People accept many kinds of arbitrary notational features when working with computers, whether it be within games, word processors or educational software. This fits in with the fact that notation is arbitrary (Hewitt, 1999) and the role of a teacher is to help students accept and memorise rather than question (Hewitt, 2001). There were two significant features which assisted this. The first was the decision not to dwell on the occasion when there was a reaction to notation and instead move on quickly to other examples where that notation would be seen again. The second significant feature was the way in which the notation was constantly being used by students to carry out tasks. This is what I will discuss next.

\section{Re-creating journeys: notation as a tool to be used rather than seen as an end product}

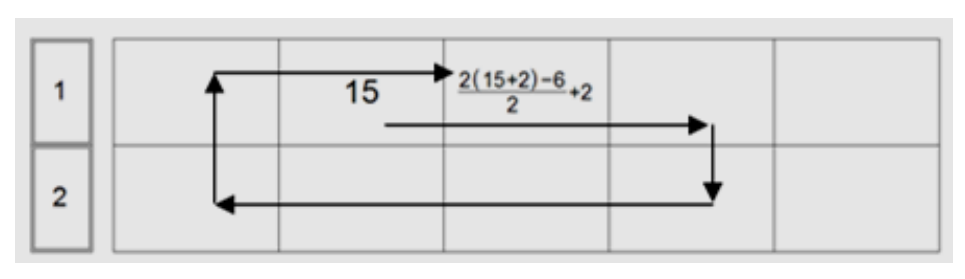

Fig 7 A journey made with the number 15

Within the first lesson, tasks were set for the class where they had to re-create an expression which had been created through a journey such as in Fig 7. Note that the middle expressions along that journey had been rubbed out. The arrows in Fig 7 were not visible on the software. They are shown here only for clarity of how the expression was created. 
The students had to examine the expression $\frac{2(15+2)-6}{2}+2$ to complete this task successfully. This contrasts with activities such as finding rules for geometric or numerical patterns where the object is to find a rule. In such tasks, the expression of that rule is often one of the last things carried out (see, for example, Ma, 2009). In such circumstances it is often unclear for students to see why they have to write this final expression in a particular way other than to please the teacher. Within the re-creating a journey activity, the notation was not an end in itself but was the tool through which this task was to be achieved. Tahta (1981) talked about inner and outer meanings for activities. The outer meaning is that which is often explicitly stated as the end point of an activity, in this case finding the succession of movements which would result in re-creating a given expression. The inner meaning is the work which needs to be carried out in order to achieve the outer meaning. In this case the inner meaning is about learning the order of operations within formal notation. So rather than explicitly telling students about order of operations, they came to know these through having to decide an order and seeing the consequences of that decision on the notation produced through their actions moving round the grid. For example, Paulette and Sofia (both judged to be working at National Curriculum (NC) level 3) were working together on a computer-generated task where they had to re-create the given expression of $2\left(\frac{14}{2}+1\right)$. They thought that addition happened before division and ended up with $\frac{14+2}{2}$. They saw that this did not look the same visually and so started again trying the division first. Fig 8 shows them having already moved 14 to the right and then up to produce $\frac{14+2}{2}$. They realised this did not look right and so they have just began to move 14 upwards to do the division first. They continued to get the final expression successfully. The feedback of seeing the notational consequence of their actions helped them to know whether the actions were in the correct order or not. So rather than the software giving negative feedback by explicitly stating that something is wrong, it gave neutral feedback which was the actual consequence of the students' actions. It was up to the students to decide whether, from this feedback, their actions were correct. I describe this form of feedback as seeing the consequences of your actions. The software provided the consequences, in terms of formal notation, of the movements made. So although the arbitrary (notation) was provided students had to educate their own awareness of the mathematical property of order within the given formal expressions.

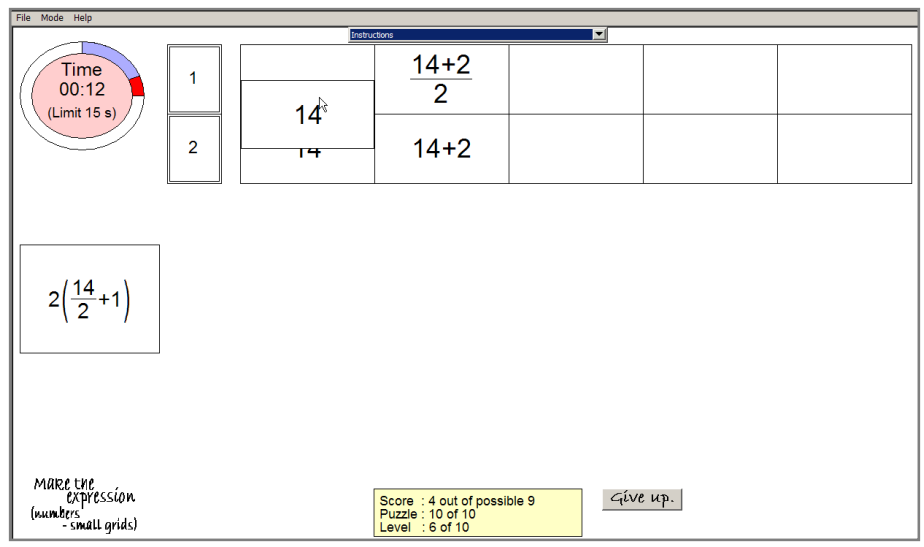

Fig 8 Having tried addition before division, Paulette and Sofia decide to do division first instead and are in the middle of moving the 14 upwards (division)

After completing a set of 10 questions, Paulette and Sofia continued with tasks at the next level where expressions now had four operations. They attempted eight questions at this level before it was time to pack up and even though these were bigger expressions, they only had an order of operations difficulty with just one expression which 
happened to involve a double division: $\frac{2\left(\frac{6}{2}\right)+2}{2}$. All the other expressions they continued to attempt at this level, such as $2\left(\frac{10}{2}+1\right)-4$, were carried out successfully within the allocated time of 15 seconds for each one. This increased confidence was indicative of all the students as their uncertainty with the order of operations gradually decreased whilst doing such activities. Abbas (judged to be $\mathrm{NC}$ level 3) was someone who was uncertain about order of operations earlier on in the second lesson. The last half an hour of that lesson, Abbas worked on computergenerated tasks that asked students to substitute values for letters in expressions (letters had been introduced by this time). He was working on substituting $b=36$ into the expression $5\left(\frac{b}{6}+1\right)$. The screen consisted of the expression already in a cell and another window with $b=36$ inside. Abbas talked about what he had learnt concerning the notation:

"It tells you $b$ equals thirty-six so you know that 36 (points to the $b$ ), this line stands for division (points to division line). So you do thirty-six divided by six, which is... six, and then you do six add one which is seven. You know the plus one goes first and not the five because the plus one is inside the brackets so you do that first. So six plus one equals seven. So these brackets stand for times and whatever is on the left hand side of it is the number that you times it by. So I do five times seven, which is... thirty-five, so thirty-five should be the answer."

Learning the order of operations requires expressions to have a certain degree of complexity, otherwise there are not enough operations present for there to be any significant issue about ordering them. Radford (2010) talks about the deliberate design of a task to be set beyond the arithmetic capabilities of the students to promote algebraic thinking. In a different but related way, algebraic expressions need to be complex enough so that they are not too simple to comprehend as a whole. They require unpacking in terms of the order of operations. There were several examples of these Year 5 students becoming excited when expressions began getting big. For example, when they had the whole group challenge of trying to re-create the expression $2\left(\frac{2\left(\frac{2(33-2)+2}{2}+3\right)-2}{2}-1\right)-4$ the noise level rose significantly with animated excitement as they used hand movements to discuss what the path might be. Far from feeling frightened of such big expressions, they appeared to relish the challenge. Joyce (NC level 3) came up and made the movements on the interactive whiteboard and occasionally she made incorrect movements but then noticed the notation was not as she was expecting and so changed her mind to what was a correct movement. Occasionally I asked her to pause asking the class "can you see this [pointing to the expression she had got so far] in here [pointing to the final large expression]?" This encouraged them to check how they were doing by comparing the visual appearance of the expressions. This meant that they could self-check whether they had made the right movements so far. The class were calling out how she should move, occasionally using words such as "down". However, after a while I asked "by down you mean what?" This shifted the language into mathematical operations rather than movements.

The fact that notation was continually being interpreted and used in working on the task helped students to become familiar and comfortable with formal notation. This was something which Van Amerom (2003) and others had identified as a major obstacle for many students. The feedback provided by the software enabled students to educate their awareness of order within the notation and consequently helped students learn how to read order of operations within formal notation without the need for mnemonics such as BIDMAS or PEMDAS. This helped students overcome, or even avoid, the parsing obstacle (Tall and Thomas, 1991). 


\section{The shift to justification when working on inverse and solving equations}

The third lesson started with a quick recap of students explaining the order of operations in a given expression. Following this, a pre-prepared file was opened as in Fig 9 and the students were asked for the first time how they could find out where the letter $x$ was. Several hands went up and there was a mix of answers offered:

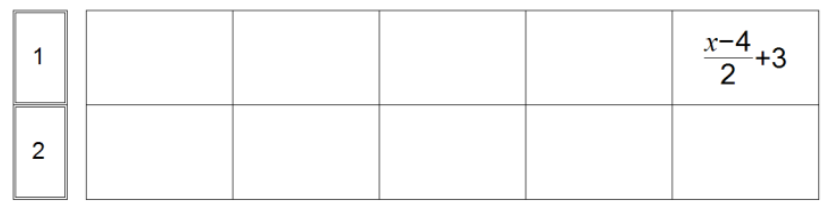

Fig 9 a pre-prepared file with the task of finding where the letter $x$ is

Ravi (NC level 3): Is it in the fourth bottom of the two times table?

Here Ravi offered a final cell without an explanation. The cell suggested was, in fact, correct. However, I wanted methods to be discussed and so chose to say that I did not know where it was myself at the moment and asked how it could be worked out. I wanted the emphasis to be on a method which could be used rather than a final answer.

Munim (NC level 4): Because you took away four, you come back four again and the place it ends on was the place you started from. So the second box on the one times table.

Munim seemed to be focused on the previous activities where students had been trying to re-create an expression and so the focus was on the existing order of operations.

Chris (NC level 5): But don't you do the expression in reverse? The whole expression in reverse, so you do, you start the other way round as well. So you start with adding three, so you take away three from that box.

Then you times by two because of the divide in the expression. Then you add four. And then you end up in the correct box.

Chris offered a clearly articulated process but I recall feeling that there were a limited number of students who looked as if they were comfortable with what was said. So another journey was made as in Fig 10(a) where this time the route was drawn out. A letter, $d$, was placed in the cell marked 1 and taken on the journey indicated to produce the expression $2(d+2)+4$ in the cell marked 4 . When the interactive whiteboard pen was pressed on that cell the expression was seen on top of the $4^{\text {th }}$ marker (Fig 10(b)). It returned to having the $4^{\text {th }}$ marker on top when the pen was released.

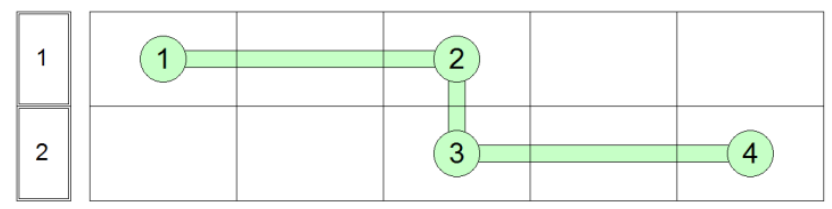

Fig 10(a) A route is indicated on the grid

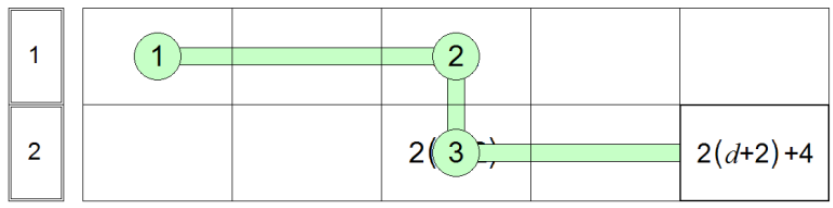

Fig 10(b) the letter $d$ dragged along that route with the final expression seen on top of the $4^{\text {th }}$ marker when the interactive whiteboard pen was pressed on that cell 
The following is a transcript of the first part of a conversation where the students worked on what was needed to be done to get back from the expression in cell marked 4 to the letter which was in the cell marked 1 . Note that when the 'inverse' button in the toolbar is pressed down a movement which happens to be the inverse of the last operation within an expression will result in that operation being cancelled. So, for example, if $2(d+2)+4$ in row 2 is moved two cells to the left it will show $2(d+2)$ rather than $2(d+2)+4-4$.

DH: OK. So if I wanted to get to find out where this was (pointing to the letter $d$ in cell marked 1), which we know where it is now don't we? What do I have to do to this (pointing to the expression in cell marked 4)?

Student 1: Do it the other way round.

DH: What do I have to do to that? What can I do? If I am here (pointing to cell marked 4), how can I get back to there (pointing to cell marked 1)?

Student 2: Take away four.

DH: Go on, say again.

Student 2: Take away four.

DH: OK. Now what I am going to do is... (clicks the 'Inverse' button on the toolbar)... by the way why did you say take away four?

Student 2: Go back.

DH: OK. So, see this here (pointing to the ' +4 ' in the expression)? I've taken away two (moving the expression one cell to the left producing the expression $2(\mathrm{~d}+2)+4-2)$. Oh, sorry, I haven't got your attention. OK? Um, I'm taking away two (repeating movement). And you want to take away four?

Student 2: Yes.

DH: What is going to happen if I take away four (pointing to ' $+4-2$ ' within expression)?

Student 3: Plus four is going to come off.

DH: What happens if I take away four after I've added four? What will happen? What's going to happen if I take away four after I've added four? What's going to happen?

Student 4: Get lost.

Student 5: Add four is going to come off the box.

Student 6: The equation will spell out wrong. It will say something wrong.

DH: (makes movement one more cell to the left which results in the expression $2(d+2)$ appearing in cell marked 3).

Student 7: Two d add...

Student 8: Two times...

DH: What has happened to the add four?

Students: [Several voices] It's come off/It's gone/It's vanished.

DH: And why did it vanish?

Students: [Many voices: unclear]

DH: Hang on a second. Shhh. One voice. Hands up. Why did it vanish? Why did it vanish? Why did it go? (Points to student 9)

Student 9: Because you added four and then you took it away.

The emphasis was now on students being asked to justify why something was the case. In this passage there were 16 times a question was asked of the class (ignoring questions of clarification). Students were being asked to justify and account for why something was the case. This was a marked difference to when students were learning to accept 
how notation was written as at that time no explanations were given or asked for. The change indicated a shift from the arbitrary notation to the realm of the necessary. There were reasons why the order of operations originally carried out now had to be reversed. Whether written in formal notation or in an idiosyncratic form of notation, it still needed to be the case that the order of operations had to be reversed and that inverse operations were carried out.

The route drawn on the grid represented a metaphorical connection with journeys and the first student in the transcript above responded in a way which linked in with that. "Do it the other way round" can be interpreted in terms of the physical journey. The choice not to pick up on that comment was based on wanting to place attention onto the notation rather than the physical movement. Instead I decided to wait until a student made a comment which was clearly about the mathematical operations. Indeed as this lesson continued the activities involved increasingly less visual support. Initially the route was shown, as in Fig 10(a). Then a journey was made but without the route marked. Finally, the grid itself was not visible and only two 'windows' could be seen showing an equation in one and the letter in the other. In this last case students had to enter into an 'Expression Calculator' what calculation they would do to solve the equation. This resembles what is required when working on paper. Reference is often made to the notion of scaffolding (Wood et al., 1976) but comparatively little is said about the important role of gradually fading any support which has been offered (Seeley Brown et al., 1989). If the desire is eventually for students to work successfully without support then the planning of fading any initial support is important.

\section{Work completed at the end of the lessons}

At the end of the last lesson students were asked to take one of two sheets. Both these sheets involved solving equations. The first sheet had pictures of routes on the grid that supported them solving the equations. The second sheet was just a collection of equations to solve without any visual support. Students were given free choice as to which sheet they worked on. Of the 18 sheets collected in (some students worked in pairs), thirteen were the sheets with visual support and five were the sheets with no support. The fact that most students went for the sheet with visual support indicated limited confidence that many students had with taking on the challenge. This may not be surprising as solving equations had only been addressed in the previous 17 minutes. There was mixed success with the solving of equations sheets, with $67.9 \%$ of questions answered across the whole group being arithmetically correct in the sense that the answer given was indeed the correct numerical solution. However, there was evidence that the algebraic process was carried out correctly for some of the answers but a mistake was made with the arithmetic. If these were considered to be algebraically correct, then the success rate changed to $72.6 \%$. There may be others where there were purely arithmetic errors but since there was no evidence of this they were considered incorrect. Many students did not feel a need to write down many, or indeed any, workings. Atiq (NC level 5) and Munim (NC level 4) worked together and managed to complete correctly the first nine questions in the 12 minutes which remained at the end of the final lesson (see Fig 11).

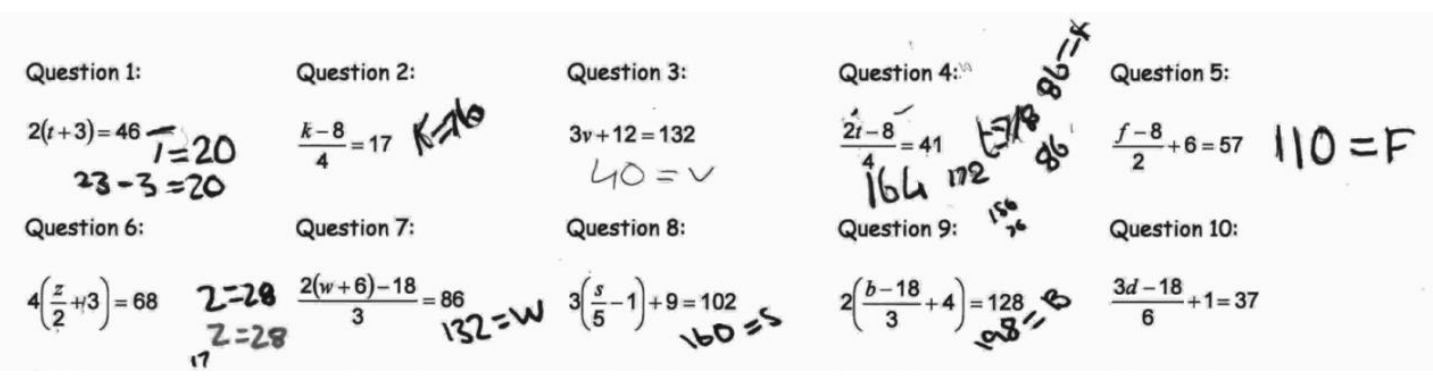

Fig 11 Equations solved by two students at the end of the third lesson

What I found of significance was the fact that when students did write expressions down, all but one pair of students who worked together, wrote them in correct formal notation (use of division line, brackets and placement of addition and subtraction signs following a division). This included those students who were identified as relatively weak and 
used the more supportive sheet. For example, Ravi (NC level 3) wrote down his solution as an expression before writing the answer of 12 (Fig 12) and perhaps the weakest student in the class, Tasmina (NC level 2), also wrote down her solution in correct notation (Fig 13).

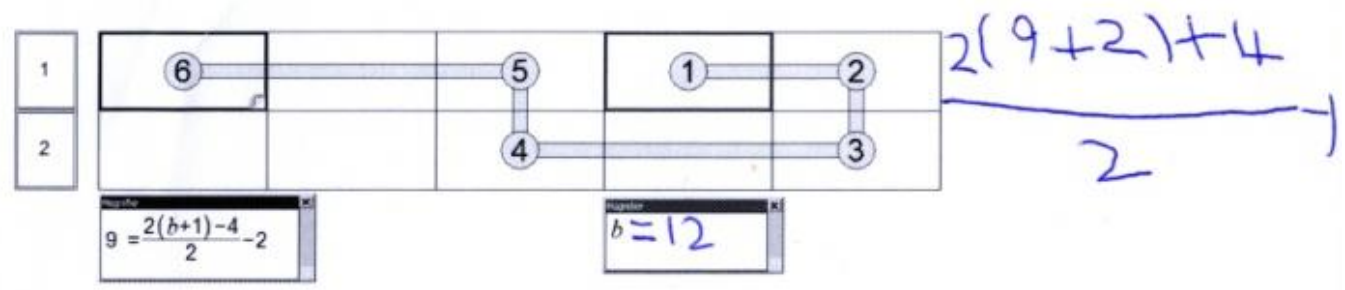

Fig 12 Ravi's written expression in correct notation
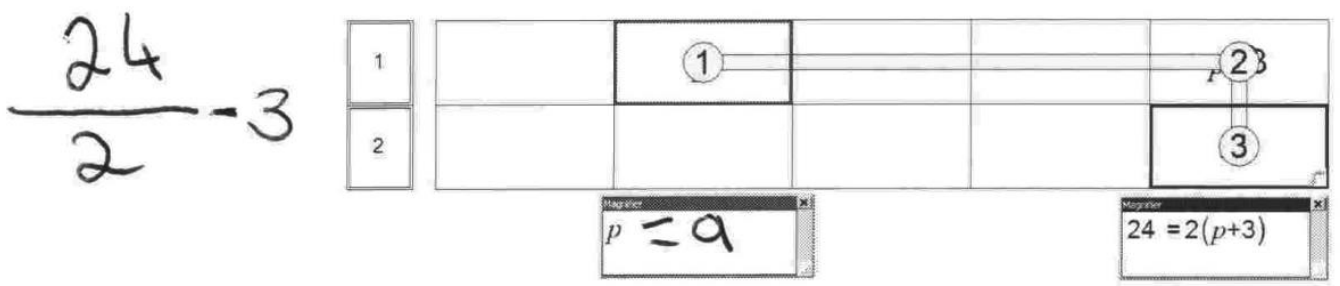

Fig 13 One of the weakest students was also writing her solutions in formal notation

Given that the students had not formally met letters in their mathematics lessons, nor had they met formal notation, the confidence with which they worked with formal notation involving letters was striking.

This raised for me the issue of learning which involved more explicit conscious attention (which included the solving of equations) compared with the more implicit nature of their learning of notational conventions. The focus was mainly on working with expressions in order to complete various tasks rather than on the form and nature of the expressions themselves. I might say that the focus was through the expressions rather than on the expressions. The role of subordination (Hewitt, 1996) in their learning of notation appeared to be significant and a strong factor in the way in which they became confident with quite complex expressions involving up to 11 operations. By subordination I mean that the interpretation of notation was required to be practised repeatedly to achieve the set tasks and the consequences of that practice was observable within the feedback offered by the software.

\section{Discussion}

I will discuss some of the issues that arose under the headings of the difficulties identified at the beginning of the paper and end with a consideration of the role of the software.

\subsection{Learning formal notation}

Students came to have considerable confidence with formal notation, even feeling excited about the idea of working with quite complex expressions involving more than 10 operations. This was despite them having significant

difficulty in the first lesson in trying to write down how some divisions might be written, such as $\frac{8-4}{2}$. A key factor was the way in which the software fed back information about movements on the grid, this information coming as a formal expression. As such, formal notation was the vehicle through which tasks concerning movement were carried out. This gave notation a subordinate role to those tasks. The notation merely denoted a series of moves which, in the context of the learning environment, had inherent meaning. Seeing the consequences of their actions 
meant that they could educate their interpretation of the notation continually as they proceeded with the tasks. At no time was the notation explained and students did not ask for explanations. Instead notation was accepted and adopted, which was appropriate for the arbitrary.

\subsection{Process/object}

The expressions created were historical artifacts of journeys made. The form of the expression had meaning in terms of a journey. A different form would have meant a different journey. For example, $2(n+3)$ would mean a different journey than $2 n+6$ even though they both start from the same cell and end at the same cell. The first few minutes of the first lesson had some students turning an expression, such as $5-2$, into a single number by writing an equals sign and carrying out the arithmetical process. However, this soon stopped and all the students became comfortable with expressions as objects in their own right with no-one overtly trying to carry out the operations.

The fact that an expression could physically be acted upon by clicking on it and dragging it to another part of the grid meant that the expression was an object to be manipulated in just the same way as a number could be manipulated. At the same time, when given a substitution task they were comfortable with carrying out the process and finding the numerical value of an expression. So the students appeared to have proceptual thinking (Gray and Tall, 1994) in that they were flexible in being able to think of an expression both as an object and as a process. APOS theory (Dubinsky, 1991; Cottrill et al., 1996) generally indicates an ordering of actions generating processes, which become objects and develop into schemas. However, the software design means that actions (movements on the grid) produce objects (notational expressions) in the first instance. It is only later that operations, or processes, are carried out on those objects, such as working out inverse operations for a given expression. So, interestingly it seems that in this case the order was AOPS rather than APOS.

\subsection{Order of operations}

The learning of order of operations was assisted by seeing expressions being built up one operation at a time through each movement on the grid. The learning continued with them seeing the consequences of their actions when trying to re-create an expression. As with Paulette and Sofia, when they incorrectly felt that addition took place first in the expression $2\left(\frac{14}{2}+1\right)$, they could tell that the notation resulting from their movements was different to the given expression and so they thought again and decided that the division must be first. An expression was the historical artifact of movements made on the grid and this context helped give a sense that order matters, as a different series of movements would result in a different expression. The activity of re-creating the expression meant that they needed to attend to order. This is something they already know implicitly from their met-before's (Tall, 2004) experience of making journeys in real life or giving someone else directions.

The students were successful at learning the order of operations without the need of any explicit teaching or the use of a mnemonic such as BIDMAS or PEMDAS. It was through the re-creating expressions activities that they developed their own sense of how to read order in an expression. This sense of order being articulated clearly by Abbas, for example. His clear understanding of order came without any exposition from a teacher and had improved significantly from his more uncertain state earlier on in that lesson. This contrasts with what Tall and Thomas (1991) identified as a parsing obstacle which can prevent students being successful in their algebraic work.

\subsection{What students can do}

Overall, Year 5 students were able to gain a success of around $70 \%$ with questions on solving linear equations after only three lessons from a starting point of never having been introduced to letters nor having met formal notation. More significantly, they were confident with reading, writing and working with formal algebraic notation including letters. This lends weight to the notion that students have the powers to learn algebraic topics successfully at 
relatively young ages and supports other studies which suggest this (for example Carraher et al., 2006; Blanton and Kaput, 2004). Moreover, this study shows that students can also work algebraically with relatively complex notation. They also did not experience, or quickly overcame, some of the common difficulties discussed at the beginning of this paper: the equals sign, seeing expressions as processes and not so much as objects, learning to accept formal notation and reading order of operations within that notation.

\subsection{The role of Grid Algebra}

The software is designed to provide what is arbitrary, the notation. It does not provide answers to arithmetic nor algebraic matters, such as carrying out arithmetic or solving an equation. The latter is in the realm of the necessary and as such students are required to engage with these challenges themselves. However, the software did provide significant feedback for these 9-10 year old students. A task such as trying to re-create an expression required students to learn order of operations within a given expression. In their attempts to re-create an expression they were assisted through seeing the notation which appeared as a consequence of the movements they made on the grid. They could observe whether the notation produced through their movements looked the same as that which appeared in the expression they were trying to re-create. This feedback was in one sense neutral as it simply reflected back the notational consequence of the movements taken. It did not make value judgments on whether the movements were correct or not. Yet the feedback enabled students to correct themselves when they went wrong and be confident when they were right. This type of neutral feedback can be found within the computer program Logo, which was more common within mathematics classrooms in the 1990s. Logo shows the geometric consequences of instructions typed in which tells the 'turtle' how far to move forwards and what angles to turn, etc. Clements et al. (1997) found that Logo provided feedback which allowed the students to reflect upon their thinking and make changes to correct their misunderstandings.

The fact that Grid Algebra fed back the consequences of movements in formal algebraic notation meant that students were forced into interpreting this formal notation in order to carry out the various tasks. This subordinate role (Hewitt, 1996) of formal notation to tasks which were understandable to students purely in terms of movements, meant that the notation became familiar to the students and they became relatively fluent and comfortable with using it.

Another feature of the software was that expressions created through movements were frequently not worked out arithmetically. They stood as historical artifacts of the journeys made to create them. In fact, if they were simplified in any way they would lose that role of a historical artifact. Thus there was a purpose to leaving the expressions as objects in their own right. Furthermore, expressions could be picked up and moved and as such were treated as objects to be moved around as much as a single number or letter. Expressions were also treated as processes on occasions when the value of an expression needed to be worked out, such as in substitution tasks. This helped students develop proceptual thinking with regard to the way in which they viewed and dealt with expressions.

\section{Final reflection}

This paper has shown that some the common difficulties identified within the literature are not an inevitable consequence of working on algebra. It also showed that relatively young students of 9-10 years of age are capable of working with complex algebraic notation with confidence and can work with that notation in a meaningful way to carry out substitution tasks and solving linear equations. Some features of the software played a crucial role in this learning. If students have the potential to be successful with this area of algebra then the fact that many students do experience difficulty raises the question of whether it is a matter of what barriers are sometimes placed in the way of their learning due to pedagogic approaches taken rather than algebra being an inherently difficult topic to learn.

\section{Acknowledgements}

Many thanks to Jim Middleton for his comments on an earlier draft of this paper. 


\section{References}

Blanton, M. L. and Kaput, J. J. (2004). Elementary grades students' capacity for functional thinking. In M. J. Høines and A. B. Fuglestad (Eds), Proceedings of the 28th Conference of the International Group for the Psychology of Mathematics Education, (Vol. 2, pp. 135-142). Bergan, Norway: PME.

Carraher, D., Schliemann, A., Brizuela, B. and Earnest, D. (2006). Arithmetic and algebra in early mathematics education. Journal for Research in Mathematics Education 37(2), pp. 87-115.

Carraher, D., Schliemann, A., D. and Brizuela, B., M. (2001). Can young students operate on unknowns? In M. van den Heuvel-Panhuizen (Ed.) Proceedings of the 25th Conference of the International Group for the Psychology of Mathematics Education, (Vol. 1, pp. 130-140). Utrecht, The Netherlands: PME.

Clements, D. H., Battista, M. T., Sarama, J., Swaminathan, S. and McMillen, S. (1997). Students' development of length concepts in a Logo-based unit on geometric paths. Journal for Mathematics Teacher Education 28(1), pp. 70-95.

Collis, K. F. (1974). Cognitive development and mathematics learning. Paper presented at the Psychology of Mathematics Workshop, (pp.). Centre for Science Education: Chelsea College, London.

Collis, K. F. (1975). The development of formal reasoning. Report of a Social Science Research Council sponsored project (HR 2434/1), (pp.). Newcastle, NSW, Australia: University of Newcastle.

Cooper, T. J., Boulton-Lewis, G. M., Atwah, B., Pillay, H., Wilss, L. and Mutch, S. (1997). The transition from arithmetic to algebra: initial understanding of equals, operations and variable. In E. Pehkonen (Ed.) Proceedings of the 21st conference of the International Group for the Psychology of Mathematics Education, (Vol. 2, pp. 89-96). Lahti, Finland: PME.

Cottrill, J., Dubinsky, E., Nichols, D., Schwingendorf, K., Thomas, K. and Vidakovic, D. (1996). Understanding the limit concept: beginning with a coordinated process scheme. Journal of Mathematical Behavior 15, pp. 167-192.

Davydov, V. V. (1975). Logical and psychological problems of elementary mathematics as an academic subject. In L. P. Steffe (Ed.), Children's capacity for learning mathematics. Soviet studies in the psychology of learning and teaching mathematics, Vol. VII, Chicago: University of Chicago, pp. 55-107.

Deacon, T., W (1997). The Symbolic Species: the co-evolution of language and the brain. New York: W.W. Norton \& Company.

Dougherty, B. J. and Zilliox, J. (2003). Voyaging from theory to practice in teaching and learning: a view from Hawai'i. In N. A. Pateman, B. J. Dougherty and J. T. Zilliox (Eds), Proceedings of the 27th Conference of the International Group for the Psychology of Mathematics Education held jointly with the 25th Conference of PME-NA, (Vol. 1, pp. 17-23). Hawai'i, USA: PME.

Dubinsky, E. (1991). Reflective abstraction in advanced mathematical thinking. In D. Tall (Ed.), Advanced mathematical thinking, Dordrecht: Kluwer Academic Publishers, pp. 95-123.

Filloy, E. and Rojano, T. (1989). Solving equations, the transition from arithmetic to algebra. For the Learning of Mathematics 9(2), pp. 19-25.

Glidden, P. L. (2008). Prospective elementary teachers' understanding of order of operations. School Science and Mathematics 108(4), pp. 130-136.

Gray, E. M. and Tall, D. O. (1994). Duality, ambiguity and flexibility: A proceptual view of simple arithmetic. Journal for Research in Mathematics Education 25(2), pp. 115-141.

Herscovics, N. (1989). Cognitive Obstacles Encountered in the Learning of Algebra. In S. Wagner and C. Kieran (Eds), Research Issues in the Learning and Teaching of Algebra, Reston, Virginia: National Council of Teachers of Mathematics, Lawrence Erlbaum Associates, pp. 60-86.

Herscovics, N. and Linchevski, L. (1994). A cognitive gap between arithmetic and algebra. Educational Studies in Mathematics 27, pp. 59-78.

Hewitt, D. (1996). Mathematical fluency: the nature of practice and the role of subordination. For the Learning of Mathematics 16(2), pp. 28-35.

Hewitt, D. (1999). Arbitrary and Necessary: Part 1 a Way of Viewing the Mathematics Curriculum. For the Learning of Mathematics 19(3), pp. 2-9.

Hewitt, D. (2001). Arbitrary and Necessary: Part 2 Assisting Memory. For the Learning of Mathematics 21(1), pp. 44-51.

Hughes, M. (1990). Children and Number. Difficulties in Learning Mathematics. Oxford: Basil Blackwell.

Kieran, C. (1981). Concepts associated with the equality symbol. Educational Studies in Mathematics 12(3), pp. 317-326. 
Knuth, E. J., Alibali, M. W., McNeil, N. M., Weinberg, A. and Stephens, A. C. (2005). Middle school students' understanding of core algebraic concepts: equivalence \& variable. ZDM 37(1), pp. 68-76.

Küchemann, D. (1981). Algebra. In K. M. Hart (Ed.), Children's understanding of mathematics: 11-16, London: John Murray, pp. 102-119.

Lee, M. A. and Messner, S. J. (2000). Analysis of concatenations and order of operations in written mathematics. School Science and Mathematics 100(4), pp. 173-180.

Linsell, C. and Allan, R. (2010). Prerequisite skills for learning algebra. In M. Pinto, M and T. Kawasaki, F (Eds), Proceedings of the 34th Conference of the International Group for the Psychology of Mathematics Education, (Vol. 3, pp. 217-224). Belo Horizonte, Brazil: PME.

Ma, H.-L. (2009). Characterizing students' algebraic thinking in linear pattern with pictorial contents. In M. Tzekaki, M. Kaldrimidou and H. Sakonidis (Eds), Proceedings of the 33rd Conference of the International Group for the Psychology of Mathematics Education, (Vol. 4, pp. 49-56). Thessaloniki, Greece: PME.

MacGregor, M. and Stacey, K. (1997). Students' understanding of algebraic notation: 11-15. Educational Studies in Mathematics 33, pp. 1-19.

Mason, J. (2002). Researching your own practice: the Discipline of Noticing. London: RoutledgeFalmer.

Mercer, N. (2000). Words and minds. London: Routledge.

Radford, L. (2010). Elementary forms of algebraic thinking in young students. In M. Pinto, M and T. Kawasaki, F (Eds), Proceedings of the 34th Conference of the International Group for the Psychology of Mathematics Education, (Vol. 4, pp. 73-80). Belo Horizonte, Brazil: PME.

Sáenz-Ludlow, A. and Walgamuth, C. (1998). Third graders' interpretations or equality and the equal symbol. Educational Studies in Mathematics 35, pp. 153-187.

Schliemann, A., Carraher, D., Brizuela, B., Earnest, D., Goodrow, A., Lara-Roth, S. and Peled, I. (2003). Algebra in elementary school. In N. A. Pateman, B. J. Dougherty and J. T. Zilliox (Eds), Proceedings of the 27th Conference of the International Group for the Psychology of Mathematics Education held jointly with the 25th Conference of PME-NA, (Vol. 4, pp. 127-134). Hawai'i, USA: PME.

Seeley Brown, J., Collins, A. and Duguid, P. (1989). Situated Cognition and the Culture of Learning. Educational Researcher 18(1), pp. 32-42.

Sfard, A. (1991). On the dual nature of mathematical conceptions: reflections on processes and objects as different sides of the same coin. Educational Studies in Mathematics 22(1), pp. 1-36.

Sfard, A. and Linchevski, L. (1994). The gains and pitfalls of reification - the case of algebra. Educational Studies in Mathematics 26, pp. 191-228.

Steffe, L. P. and Olive, J. (1996). Symbolizing as a constructive activity in a computer microworld. Journal of Educational Computing Research 14(2), pp. 113-138.

Strauss, A. and Corbin, J. (1990). Basics of Qualitative Research: Grounded Theory Procedures and Techniques. London: SAGE publications Ltd.

Tahta, D. (1981). Some thoughts arising from the new Nicolet films. Mathematics Teaching 94, pp. 25-29.

Tall, D. (2004). Thinking through three worlds of mathematics. In M. J. Høines and A. B. Fuglestad (Eds), Proceedings of the 28th Conference of the International Group for the Psychology of Mathematics Education, (Vol. 4, pp. 281-288). Bergan, Norway: PME.

Tall, D. and Thomas, M. (1991). Encouraging Versatile Thinking in Algebra Using the Computer. Educational Studies in Mathematics 22, pp. 125-147.

Van Amerom, B. A. (2003). Focusing on Informal Strategies When Linking Arithmetic to Early Algebra. Educational Studies in Mathematics 54(1), pp. 63-75.

Wood, D., Bruner, J. S. and Ross, G. (1976). The role of tutoring in problem solving. Journal of child psychology and psychiatry 17, pp. 89-100. 